\title{
Facilitating Organizational Change to Accommodate an Inpatient Portal
}

\author{
Daniel M. Walker ${ }^{1,2,3,4}$ Alice Gaughan ${ }^{2}$ Naleef Fareed ${ }^{2,3}$ Susan Moffatt-Bruce $2,3,5$ \\ Ann Scheck McAlearney ${ }^{1,2,3,4}$
}

\footnotetext{
${ }^{1}$ Department of Family Medicine, College of Medicine, The Ohio State University, Columbus, Ohio, United States

${ }^{2}$ Center for the Advancement of Team Science, Analytics, and Systems Thinking (CATALYST), College of Medicine, The Ohio State University, Columbus, Ohio, United States

${ }^{3}$ Department of Biomedical Informatics, College of Medicine, The Ohio State University, Columbus, Ohio, United States

${ }^{4}$ Division of Health Services Management and Policy, College of Public Health, The Ohio State University, Columbus, Ohio, United States

${ }^{5}$ Department of Surgery, College of Medicine, The Ohio State University, Columbus, Ohio, United States
}

Appl Clin Inform 2019;10:898-908.
Address for correspondence Ann Scheck McAlearney, ScD, MS, Center for the Advancement of Team Science, Analytics, and Systems Thinking (CATALYST), College of Medicine, Ohio State University, 460 Medical Center Drive, Suite 530, Columbus, OH 43210, United States (e-mail: Ann.McAlearney@osumc.edu).

\begin{abstract}
Keywords

- patient portals

- implementation

- organizational culture

- hospitalization

- nursing informatics

- engagement

- organizational change

Background Patient portals are becoming more commonly used in the hospital inpatient setting. While the potential benefits of inpatient portals are acknowledged, there is a need for research that examines the challenges of portal implementation and the development of best practice approaches for successful implementation.

Objective We conducted this study to improve our understanding of the impact of the implementation of an inpatient portal on care team members in the context of a large academic medical center. Our study focused on the perspectives of nursing care team members about the inpatient portal.

Methods We interviewed care team members $(n=437)$ in four phases throughout the 2 years following implementation of an inpatient portal to learn about their ongoing perspectives regarding the inpatient portal and its impact on the organization.

Results The perspectives of care team members demonstrated a change in acceptance of the inpatient portal over time in terms of buy-in, positive workflow changes, and acknowledged benefits of the portal for both care team members and patients. There were also changes over time in perspectives of the care team in regards to (1) challenges with new technology, (2) impact of the portal on workflow, and (3) buy-in. Six strategies were identified as important for implementation success: (1) convene a stakeholder group, (2) offer continual portal training, (3) encourage shared responsibility, (4) identify champions, (5) provide provisioning feedback, and (6) support patient use.

Conclusion Inpatient portals are recognized as an important tool for both patients and care team members, but the implementation of such a technology can create challenges. Given the perspectives care team members had about the impact of the inpatient portal, our findings suggest implementation requires attention to organizational changes that are needed to accommodate the tool and the development of strategies that can address challenges associated with the portal.
\end{abstract}

received

August 5, 2019

accepted after revision

September 18, 2019 (c) 2019 Georg Thieme Verlag KG Stuttgart - New York
DOI https://doi.org/

10.1055/s-0039-1700867.

ISSN 1869-0327. 


\section{Background and Significance}

Hospitals are increasingly recognizing the potential of patient-facing technology to facilitate patient engagement and experience. ${ }^{1,2}$ Inpatient portals are one technological tool that hospitals can use to transform their healthcare to become more patient-centered and, in turn, improve health outcomes. ${ }^{3-5}$ Inpatient portals are applications specifically designed for the acute-care setting that offer a patient access to their health information during a hospital admission. These applications are connected to an institution's electronic health record (EHR) and provide the ability for patients to view their upcoming schedule and current medication lists, view their laboratory and diagnostic test results, send messages to their care team, order meals, and access patient education materials.

The evidence base for inpatient portals is growing, and recent research suggests that patients provided with an inpatient portal have lower readmission rates and are more likely to search for information online. ${ }^{6,7}$ While these outcomes are promising, other researchers have focused attention on upstream factors that contribute to the success of inpatient portals, such as their use $\mathrm{e}^{6-10}$ and usability, ${ }^{11-14}$ the patient's experience of the portal, ${ }^{15-18}$ and the care team's expectations of and experience with the portal. ${ }^{19-22}$ This evidence provides insight into the nuanced ways in which different stakeholders interact with the technology. Importantly, the growing evidence regarding inpatient portals highlights the collaborative aspects of the technology between the patient and the care team with both optimistic potential and cautious pragmatism. ${ }^{23,24}$ This tension stems from the expectations and early evidence of outcomes associated with inpatient portals combined with the challenges related to implementing an inpatient portal into the complex work environment of the hospital.

These challenges arise from the effort needed to modify care team members' attitudes related to workflow changes to accommodate the new technology. ${ }^{25}$ However, prior work has viewed implementation of an inpatient portal as a onetime event rather than considering the organizational change as a process that requires changing the care team's perspective. As a result, the existing literature may be limited in its ability to provide practical guidance to hospitals as they implement inpatient portals. Alternatively, viewing organizational change as a process, an approach often considered in the implementation of new technologies into healthcare, ${ }^{26}$ can help highlight ways in which the care team can effectively manage and realize the change initiated (i.e., implementing the inpatient portal). Considering implementation as a process additionally allows one to consider how care team perspectives have adapted over time to the change, and how they have managed the expected and unexpected challenges associated with the change. These issues are particularly relevant to technologies such as inpatient portals that require collaboration between the care team and patients in novel ways, such as configuring the application for the patient or answering questions about the content in the application.

\section{Objectives}

This study aims to improve our understanding about changes in the care team's perspectives about an inpatient portal following its implementation in the context of a large academic medical center. This investigation will provide practical guidance for hospitals interested in implementing an inpatient portal to help them address challenges that may limit the potential for this innovative tool to improve the patient centeredness of hospital care.

\section{Methods}

\section{Study Setting}

The study was conducted at a large Midwestern Academic Medical Center (AMC) that implemented Epic's MyChart Bedside, an inpatient portal, across six hospitals from August to October 2016. Upon admission, nurses conduct an assessment to determine if the patient should be offered an Android tablet equipped with the MyChart Bedside application, based on the following criteria: over age 18, English speaking, nonprisoner, and physically and cognitively capable of managing the technology. After the patient agrees that they would like access to the tablet during their hospital stay, the care team provisions the tablet, syncs it with the patient's EHR, and instructs the patient to create an account and personal identification number. The tablet is connected to the internet so that patients can also use it for other purposes such as accessing social media, email, and entertainment.

As part of the implementation process, the AMC established an inpatient portal optimization team ("Optimization Team"). This team is led by nursing administration and nursing informatics specialists. Since the implementation began, nurse managers and assistants on each unit attend monthly committee meetings where information is shared about the inpatient portal. Agenda items for discussion include updates and reporting metrics on tablet provisioning and activation rates and goals, work flows, tip sheets, training modules, tablet features, and research findings. Research team members attended these meetings to document the implementation process.

\section{Study Design}

Between September 2016 and November 2018, we conducted a qualitative study consisting of four phases of care team member interviews following implementation of the inpatient portal. Care team members were recruited to participate from 53 inpatient units of the AMC where MyChart Bedside had been implemented. Interviewers were members of the research team and did not have clinical experience or direct experience with MyChart Bedside.

Interviews were held during normal work hours in the unit break rooms to accommodate available unit staff in oneon-one or group interviews. This same approach was used across interview phases; thus, some interviewees may have participated in more than one interview phase. Using a semistructured interview guide, interviewers asked care team members questions about the impact of the inpatient 
portal on their workflow, their familiarity with portal features, and their perceptions about best practices for portal implementation. All of the interviews were audiorecorded, transcribed verbatim, and de-identified. The interview length ranged from 5 to 20 minutes, averaging 10 minutes. The Institutional Review Board of the authors' institution, The Ohio State University, approved this study.

\section{Data Collection}

We interviewed 437 care team members in person across four phases of interview, as shown in -Table 1. Care team members represented staff with multiple roles on the nursing care team including patient care associates (PCAs; i.e., nursing assistants), unit clerical associates (UCAs), and nurses (i.e., floor nurses, nurse managers). Phase 1 interviews $(n=109)$ occurred in September 2016 which was within the first month following portal implementation. Phase 2 interviews $(n=112)$ took place in June 2017, followed by phase 3 interviews $(n=116)$ in February 2018 and, lastly, phase 4 interviews $(n=100)$ in November 2018, as shown in -Table 1. For the purposes of this study, we considered phase 1 and phase 2 interviews as early postimplementation and phase 3 and phase 4 interviews as late post-implementation.

\section{Data Analysis}

The primary aim of our analysis was to understand how the AMC worked to change care team attitudes toward the inpatient portal and improve acceptance of the technology. To accomplish this goal, our analysis took a retrospective approach to examine our interviews as well as our notes about the implementation process from attendance at the Optimization Team meeting.

To begin, care team member interviews were transcribed and then analyzed, both inductively and deductively, consistent with rigorous qualitative methods. ${ }^{27}$ The first part of our analysis focused on the early post-implementation phase interviews. For these transcripts, we examined attitudes toward the inpatient portal and identified challenges with organizational change that emerged from the data. A preliminary coding dictionary was developed from questions in the semistructured interview guide. ${ }^{28}$ Then, using a grounded theory approach to substantive coding, ${ }^{29}$ two members of the team coded all the early phase interviews. The coding team, overseen by the lead investigator, met regularly throughout the coding process to ensure consistency in coding. As new themes emerged from the data, new iter- ations of the coding dictionary were developed, and coders recoded transcripts to include the new codes.

Next, using the same coding dictionary and coding process, coders coded the late post-implementation interviews. This approach allowed for comparison of themes across time to identify organizational challenges and changes over time. Finally, to identify strategies that the organization deployed to address these challenges and approaches that contributed to changing perspectives regarding the inpatient portal, we examined both the interviews and notes from the Optimization Team meetings. Our approach thus enabled us to identify and characterize strategies that emerged from our analysis as having successfully improved attitudes toward the inpatient portal. We used the ATLAS.ti software (version 8.3.1) to support the coding and analysis process. ${ }^{30}$

\section{Results}

\section{Perspectives of Care Team Members that Changed Over Time}

Our analysis identified three challenges to acceptance of the inpatient portal that were evident in the early post-implementation interviews and appeared to improve by the late post-implementation interviews: (1) difficulty with new technology, (2) difficulty integrating the inpatient portal into workflow, and (3) issues related to inpatient portal buy-in. These challenges are each described next, with additional supporting quotations presented in - Table 2 .

\section{Difficulty with the New Technology}

During the early period following inpatient portal implementation, comments from care team members suggested they were concerned with their lack of familiarity with the new technology. This concern created anxiety and frustration as one nurse explained, "Honestly we rush through it, because it's a pain. You know? And, I wish there were someone that had time to spend with them, to show them." Similarly, another care team member noted, "It's just like when you have a busy assignment, that's the lowest priority thing that you're thinking about is like getting someone a tablet."

Concerns about the new technology, however, were considerably less evident in the late post-implementation interviews. Care team members appeared more accepting of the new technology, with several noting there had been a positive impact of the portal implementation on both care team members and patients. As one nurse explained, "I'm really

Table 1 Interviewees, by type and by interview phase

\begin{tabular}{|l|c|c|c|c|}
\hline \multirow{2}{*}{} & \multicolumn{2}{|l|}{ Early post-implementation } & \multicolumn{2}{l|}{ Late post-implementation } \\
\cline { 2 - 5 } & Phase 1 & Phase 2 & Phase 3 & Phase 4 \\
\hline Nurses & 79 & 80 & 75 & 17 \\
\hline Patient care associates & 25 & 26 & 30 & 11 \\
\hline Unit clerical associates & 5 & 6 & 11 & 100 \\
\hline Total & 109 & 112 & 116 & 12 \\
\hline
\end{tabular}


Table 2 Changing perspectives of the care team over time

\begin{tabular}{|c|c|c|}
\hline Challenges & Early post-implementation & Late post-implementation \\
\hline $\begin{array}{l}\text { Difficulty with new } \\
\text { technology }\end{array}$ & $\begin{array}{l}\text { "Although it shouldn't be, it's a lower pri- } \\
\text { ority. We're trying to get other stuff done } \\
\text { and then we're like oh, we also have to get } \\
\text { them a tablet and teach them about it and } \\
\text { it's going to take time you know." } \\
\text { "So, I think that it's difficult to take the time } \\
\text { to give the iPad to the patient. So maybe } \\
\text { we'll just get better at it. I am so very } \\
\text { confused on how to actually sign one out } \\
\text { and give it to the patient." }\end{array}$ & $\begin{array}{l}\text { "We like to bring on new technology and we } \\
\text { want what's best for our patients. So I can } \\
\text { speak very highly as to them and really } \\
\text { giving this a solid push and support." } \\
\text { "I think the staff has become less afraid of } \\
\text { them. Like they are starting to see the } \\
\text { advantages of having them, letting the } \\
\text { patients having them and how it takes away } \\
\text { from some of the things, it makes the } \\
\text { patients more independent." }\end{array}$ \\
\hline $\begin{array}{l}\text { Difficulty integrating the } \\
\text { inpatient portal into } \\
\text { workflow }\end{array}$ & $\begin{array}{l}\text { "I do think like it's good-I mean I think it's } \\
\text { the right idea for them to be able to see their } \\
\text { labs of like empowering people to know } \\
\text { about their healthcare and just take you } \\
\text { know initiative and learning about it, but } \\
\text { sometimes it increases our workflow when } \\
\text { we have a lot of other things going on." } \\
\text { "I would say yeah. It's just incorporating it in } \\
\text { the workflow. A lot of us are already really } \\
\text { overextended so it's hard to add initiating } \\
\text { MyChart Bedside to our workflow. One } \\
\text { more thing to our routine and our } \\
\text { responsibilities." }\end{array}$ & $\begin{array}{l}\text { "I think initially there was probably a } \\
\text { downswing like, why do I have this new } \\
\text { added work to my day. Now I don't hear } \\
\text { anything about it, it's just workflow." } \\
\text { "I think over the course of it being introduced } \\
\text { to the unit and where it is at now I think it has } \\
\text { become more embraced... originally there } \\
\text { was a lot of hesitation because it did increase } \\
\text { the workload, it was a change, there's always } \\
\text { some resistance to change, and it required a } \\
\text { lot of I think direction from people who aren't } \\
\text { as tech savvy... but I think now is really become } \\
\text { more adopted and just engrained into the } \\
\text { everyday workflow." }\end{array}$ \\
\hline $\begin{array}{l}\text { Issues related to inpatient } \\
\text { portal buy-in }\end{array}$ & $\begin{array}{l}\text { “I just think it's something new to nurses so, } \\
\text { and like with anything with new it's hard to get } \\
\text { activated especially in organizing your day l'm } \\
\text { just happy to get, try to get people and I think } \\
\text { it's a bigger push once we're hiring new people } \\
\text { and making sure this is the type of initiative we } \\
\text { have in the hospital." } \\
\text { "I think the big thing is we talk about them at a } \\
\text { lot of these meetings is staff buy-in and it's you } \\
\text { don't understand, some don't understand } \\
\text { that this is a satisfier, patients want something } \\
\text { to do, they are bored in their rooms, they can } \\
\text { connect with their families, they want to be } \\
\text { more involved in their healthcare." }\end{array}$ & $\begin{array}{l}\text { "The more the patient uses the tablet the } \\
\text { more time that it takes away from the nurse } \\
\text { on having to explain things to them or talk } \\
\text { to them because they have the tablet. So, it } \\
\text { kind of gives time back to the nurses." } \\
\text { "I think people are starting to see the value } \\
\text { because it does occupy the patients...." }\end{array}$ \\
\hline
\end{tabular}

busy, so I mean I make time. I think it's important, so. You know it only takes a few minutes, it's not a big deal." Another care team member noted, "I provision it and activate it and all of that so it is kind of per unit on what will happen. But it's been pretty, I mean I haven't really had any trouble with it."

Difficulty Integrating the Inpatient Portal into Workflow During the early post-implementation phase, the workflow impact of patients having the inpatient portal was a common concern. One nurse shared, “I mean it's okay. I think it's good for the patients. It's just been tough sometimes to include it into your workflow. Just to get used to it, get used to asking, used to collecting them. It's just a little, I don't know, it's just I'm just not used to it. You know what I mean?" Another nurse similarly noted, "We are trying to build it in as part of the admitting process and it's a struggle."

In the late post-implementation interviews, the impact of the tablet on workflow was perceived as less of a concern compared with the perspectives from the earlier interviews. One nurse manager commented, "I think my nurses are kind of looped through the process of handing it out. I mean maybe it's so hardwired they don't even think about it." Similarly, another nurse shared, "I don't think that it's interfered with my workflow. It's just something that I have to chart and if patients ask for it [tablet] I have to. It's something I have, me or the PCA has to get them."

\section{Issues Related to Inpatient Portal Buy-in}

Comments from care team members in the early period following implementation suggested difficulty with buy-in and acceptance of the inpatient portal. One nurse lamented:

You can educate and educate and educate and people still won't buy-in. But how this is going to benefit their job is going to be key. You know, how does this MyChart Bedside 
affect your work as an RN [registered nurse]? Obviously, we put our patients first, but in order for patients to get the MyChart Bedside, we have to have our staff be engaged and willing to push that to our patients.

Another nurse noted, "I think for the buy-in, for people offering the tablets, it ... it's one of those things that's hard because people are already so busy and trying to incorporate it."

In the late post-implementation interviews, comments from care team members suggested that buy-in of the inpatient portal had improved over time. One care team member reflected, "Now, I think there is a lot of acceptance that this is just something we do." Similarly, another care team member noted:

Well, you know you have to think about whenever you are initiating anything, you're going to have to get buy-in... it's a team effort because there is value in it. The tablets offer education, they offer patients can look at medication side effects, they can play games, good pain distractor, that type of thing, help pass some time.

\section{Strategies to Address Challenges of Inpatient Portal Implementation}

Through our analysis of the Optimization Team notes and coding and analysis of the care team member interviews, six strategies emerged that appeared to help mitigate portal implementation challenges and led to the changed perspectives over time. These included the following: (1) convene a stakeholder group, (2) offer continual portal training, (3) encourage shared responsibility, (4) identify champions, (5) provide feedback about provisioning rates, and (6) support patient use. Our data allowed us to identify how the strategies developed, including their source of origin, and whether they were deliberate or emergent. Below we describe each of these six strategies, with additional supporting quotations presented in - Table 3 .

Strategy 1: Convene a stakeholder group. In response to the challenges identified during the early post-implementation phase, AMC leadership established an inpatient portal stakeholder group 6 months after the implementation had begun. This team consisted of representatives from hospital leadership (e.g., executive director), nurse managers, faculty physicians, patient experience and education leadership,

Table 3 Strategies for portal implementation success

\begin{tabular}{|c|c|c|}
\hline Strategy & Key components & Quotes \\
\hline $\begin{array}{l}\text { 1. Convene a } \\
\text { stakeholder group }\end{array}$ & $\begin{array}{l}\text { - Representatives from } \\
\text { multiple disciplines } \\
\text { involved in patient care } \\
\text { and hospital operations } \\
\text { - Communication of data } \\
\text { about inpatient portal } \\
\text { use to nurse managers } \\
\text { - Provide institutional } \\
\text { support }\end{array}$ & [Not referenced in interviews] \\
\hline $\begin{array}{l}\text { 2. Offer continual } \\
\text { portal training }\end{array}$ & $\begin{array}{l}\text { - Electronic learning } \\
\text { modules } \\
\text { - Opportunities for care } \\
\text { team members to use } \\
\text { the inpatient portal } \\
\text { - Unit visits by nursing } \\
\text { education to train/re- } \\
\text { train the care team }\end{array}$ & $\begin{array}{l}\text { "So ongoing now is different than before implementation. Because as we } \\
\text { implement units who have super-user classes, we try to get the excitement } \\
\text { going and then they would take that knowledge back to their units to share } \\
\text { and they would be the experts, the unit experts. Now that we are } \\
\text { implemented almost everywhere, pretty much everywhere, we have an e- } \\
\text { learning that new orientees take as part of their all their e-learning } \\
\text { packages. They can do it hands-on practice in the classroom of the tablets. } \\
\text { We have tablets in our training room they can use." } \\
\text { "We just really just like keep bringing it up, talking about it, getting people } \\
\text { to actually look at the tablets with the patients to see what is on there too; } \\
\text { sometimes we (and I haven't done this in a while) but at least initially we } \\
\text { pulled up the playground so people could actually look at it and play with it } \\
\text { and try to do that a bunch especially when we were still working on buy-in." }\end{array}$ \\
\hline $\begin{array}{l}\text { 3. Encourage } \\
\text { shared } \\
\text { responsibility }\end{array}$ & $\begin{array}{l}\text { - Communicating that it } \\
\text { is not one person's (or } \\
\text { role's) job, but every- } \\
\text { one's job }\end{array}$ & $\begin{array}{l}\text { "Pretty much everyone, the main person when they are admitted, the UCA } \\
\text { is responsible for going in, greeting them, and provisioning the tablet. If the } \\
\text { UC's unavailable then the PC and/or the nurse, but everyone on the floor is } \\
\text { responsible." } \\
\text { "Yeah we all do it. The nurses can do it, PCAs can do it." }\end{array}$ \\
\hline $\begin{array}{l}\text { 4. Identify } \\
\text { champions }\end{array}$ & $\begin{array}{l}\text { - Nominate initial } \\
\text { champions on each unit } \\
\text { - Recognize emergent } \\
\text { champions }\end{array}$ & $\begin{array}{l}\text { "Yeah, it's just introducing new things takes time. It worked really well } \\
\text { when we had tablet champions or something and there was a PCA and a } \\
\text { nurse that was going around making sure that patients had their tablets } \\
\text { and pushing the nurses more to play with them and help pass them out } \\
\text { more... so it's easier for us now." }\end{array}$ \\
\hline
\end{tabular}


Table 3 (Continued)

\begin{tabular}{|c|c|c|}
\hline Strategy & Key components & Quotes \\
\hline & & $\begin{array}{l}\text { "As we implement units who have super-user classes, we try to get the } \\
\text { excitement going and then they would take that knowledge back to their } \\
\text { units to share and they would be the experts, the unit experts." }\end{array}$ \\
\hline $\begin{array}{l}\text { 5. Provide feed- } \\
\text { back about provi- } \\
\text { sioning rates }\end{array}$ & $\begin{array}{l}\text { - Monthly reports to unit } \\
\text { managers including } \\
\text { activation rates, } \\
\text { averages, and goals }\end{array}$ & $\begin{array}{l}\text { "Typically email ... in the beginning when we were first getting started and } \\
\text { trying to you know make sure we got to target or goal, we also included it in } \\
\text { our huddle, we have a shift change huddle so we were also updating that } \\
\text { weekly in our huddle, but now that we've been consistently as I've } \\
\text { mentioned } 95 \text { and above, I'm sending that out in email." } \\
\text { "It is something that we talk about and we report on in staff meetings or } \\
\text { even we even have little outside shift changes to say, 'Okay this is our } \\
\text { percentage, it's like } 20 \text { or } 30 \text { percent, so let's use them.' But that's great and } \\
\text { all but I think we need to talk a little bit more. I think it's constant reminders } \\
\text { too." }\end{array}$ \\
\hline $\begin{array}{l}\text { 6. Support patient } \\
\text { use }\end{array}$ & $\begin{array}{l}\text { - Comprehensive } \\
\text { messaging to patients } \\
\text { about the value of the } \\
\text { inpatient portal }\end{array}$ & $\begin{array}{l}\text { "I tell them that they can see chart, medicines, charts, their results, send a } \\
\text { message to your doctor, also use for entertainment if you want to get on } \\
\text { the internet or things like that too." } \\
\text { "I kind of just go over the entire tablet with the patient you know the } \\
\text { MyChart Bedside, explain that step-by-step, they create a password. I kind } \\
\text { of, I'll help them with their first meal because that can kind of be a little } \\
\text { complicated to do for the first time. Help them order their meals on there } \\
\text { and you know I kind of just give them a brief overview of it." }\end{array}$ \\
\hline
\end{tabular}

information technology representatives, and members of the research team. The aim of this stakeholder group was to maximize inpatient portal use throughout the AMC.

The stakeholder group met monthly to set goals and establish priorities around inpatient portal use, discuss tablet provisioning processes and rates of activation, and examine use of the available device functions. Additionally, the team receives, analyzes, and adjudicates new or modified requests for additional features or new functionality. The creation of the stakeholder group provided a forum for the research team to communicate relevant findings to operational team members, and for stakeholders representing a range of interests to collaborate on approaches to improving acceptance of the inpatient portal. Establishment of this stakeholder group also helped facilitate the implementation of the remaining five strategies described next.

Strategy 2: Offer continual portal training. Given findings in the early post-implementation interviews about care team members' difficulties with the new technology, the research team recommended the development and deployment of additional inpatient portal training. The stakeholder group initiated the development of new online learning modules, and recommended unit visits by nursing leadership to train and re-train care team members about the portal and allow them time to use the portal. These new training opportunities were aligned with the hospital's routine practices for ongoing training and, as a result, were well received by care team members. One nurse shared:

I believe that hospital-wide, that there can always be continuing education on how it works and how it can benefit both the patient and the staff and the plan of care in general. Because we kind of tend to hit things and then it goes a few months and then no one hears any ... and then staff forget about it.

Regarding the portals, another nurse explained:

They get trainings for this. It's part of our routine. There are a few orientations every other week the groups go through. It's part of the training that they do. It's an elearning. They have the opportunity for hands on if they want to, so a lot of it is up to them to take in. We know what we give them but there's reinforcement that we do at times go around doing.

Strategy 3: Encourage shared responsibility. To help make workflow changes to accommodate the inpatient portal, nurse managers on several units communicated to their staff that all care team members on the unit were responsible for provisioning the tool to patients and answering questions about the inpatient portal. This approach was a shift in thinking, as portal provisioning had formerly been viewed as the responsibility of the UCA or PCA. One nurse manager explained this change:

So I helped implement it on the unit when it first came out, and do the staff education, and do some patient educational, getting the staff involved. And we've been able to see it progress to the point where this is all staff driven. We worked to have it be done as a team so between the nurses and the PCAs and the UCAs. But it's not just any one person's responsibility. That if the UCA sees we haven't offered to someone, they can call anyone on the 
care team and ask them to offer. And if the patient has questions, they can ask the nurse or the PCA and they can answer. So, our numbers [provisioning and activation rates] truly reflect that it's actually staff driven.

This collective approach to managing the new technology was shared at the Optimization Team meetings and adopted as a useful strategy by nurse managers from other units. A nurse from one of these additional units thus similarly noted:

Like when they have questions with the tablets or such really, we just all kind of work as a team and kind of make sure that everybody is helping out. If somebody needs something charged or help ordering food on them or whatever, then you just kind of go in and help them no matter if it is your patient or not. We all just kind of work as a team.

Strategy 4: Identify champions. Recognizing that buy-in was critical, the Optimization Team tasked each unit's nurse manager to appoint "super-users" for the unit to be inpatient portal champions at the beginning of implementation. These super-users could be nurses, nurse managers, PCAs, or UCAs. They received comprehensive portal training and were identified as unit experts to address portal-related concerns. In addition, emergent champions, those individuals who were excited about the new technology and interested in supporting use on the unit, were subsequently identified.

Care team members suggested that having portal champions available to help with technical issues related to the portal was key to the success of portal implementation and use. One nurse explained:

I think I utilized the super-user more than anything [laughing]. Especially ... with setting up an IHIS [Integrated Health Information System] [account] with the patient lists. That's kind of what I had a hard time figuring out, was getting that set up. But ...I had a super-user that helped me with it so made it easy. Fortunately, we had some help [laughing].

\section{Another nurse noted:}

I think just the constant focus on it. You know when you stop talking about something, you stop using it. So just the constant efforts that we are doing. So we have our assistants are kind of the super-users of the tablets. We have a meeting every month. The assistant nurse managers do because they are like the super-users so they are the ones pushing it and trying to keep it going.

Strategy 5: Provide feedback about provisioning rates. Findings from the research team regarding issues related to buy-in prompted their suggestion to the stakeholder group to develop a feedback mechanism for the units. As a result, a reporting process was developed to provide details about unit provisioning rates (i.e., the proportion of patients who were offered a tablet), activation rates (i.e., the propor- tion of patients who accepted and activated their tablet), and rate goals. These reports were then distributed weekly to the Optimization Team to be shared with units across the AMC. This feedback about portal provisioning rates was highlighted by care team members as a driver of their success with portal usage. As one nurse manager explained:

We get a weekly MyChart Bedside provisioning rate, documentation rate, and we send that out to the staff every week so that they know where we are. It's just something that we look at. And I think that may help, weekly to tell them where we are at. 'Hey, you guys really dropped off. We really need to get back up.' Making sure we are provisioning and giving them to patients and here is why. Making sure we are letting them know the why.

A nurse similarly reflected, “Our manager comes up and gives a report.... So, we get to see how many tablets we give out in a day, how many was returned, and stuff like that. But, a majority of the time the manager comes up and tells us in huddle."

Strategy 6: Support patient use. Stakeholder group members also recognized that patient interest in the inpatient portal would help increase care team buy-in, given the care team's concern for improving the patient care experience. As a result, the stakeholder group initiated an effort for nurses to consistently introduce the portal to patients. This introduction process included describing each of the different features of the portal and how the portal and its features can help the patient during their hospital stay. ${ }^{16,19}$ Use of this new introduction and additional messaging about the portal worked to not only convince patients about the benefits of using the inpatient portal but also to increase care team buyin. One nurse explained:

If we're maximizing our utilization - if we're not just saying, 'Hey would you like a tablet,' but if we're explaining to them, 'Hey we have this tablet that has the ability for us to more clearly show you and involve you in their care and it could do X, Y,Z, and it'll help us work as a team to get you better and home,' I think we can do a lot more with that. And I think that would definitely drive patient satisfaction higher.

\section{Discussion}

Inpatient portals are a new technology that holds potential to improve patient experience and engagement during a hospitalization-critical factors that hospitals are seeking to maximize. As a result, hospitals are increasingly considering implementing this technology. However, the organizational change that takes place with the introduction of inpatient portals into the complex work system of a hospital requires shifting perspectives of the care team. To better understand and provide guidance for future hospitals implementing inpatient portals, we evaluated the changes in perspectives experienced over 2 years following implementation system- 
wide across an AMC. Briefly, we found that change occurred in attitudes related to the new technology, changes in workflow, and buy-in about the inpatient portal. Furthermore, we identified six strategies that contributed to bringing about this change and the success of the implementation effort.

The organizational change process brought about by the implementation of a new technology into the hospital work system has been described with respect to other technologies, such as EHRs. ${ }^{26}$ While inpatient portals share some similarities to EHRs, they differ in a fundamental way: they require both care team and patient interaction and buy-in. This collaborative aspect of inpatient portals may compound initial implementation challenges, such as comfort with the technology and buy-in issues. ${ }^{24}$ Similarly, hospitals need to not only support care team use of the new technology, but patients' use as well-leading to institutional hurdles in providing appropriate training and support during implementation. Perhaps unsurprisingly, our analysis identified these themes as critical in the early post-implementation period.

On the other hand, our findings regarding changing perspectives over time and the strategies that contributed to these changes suggest that collaborative aspects of the inpatient portal present implementation opportunities. Viewing the inpatient portal as a tool that can help patients may contribute to care team members' willingness to learn about the new technology, to troubleshot workflow issues, and to garner support and buy-in for the new technology. This emphasis on patient care emerged as a key driver to the success of the six strategies to improve implementation success, and in care team member support of patients' use of the technology. Likewise, comprehensive messaging from the AMC about the importance of providing the inpatient portal to patients was essential and reinforced care team acceptance of the technology. This included emphasizing the benefits to patients such as increasing patient engagement, offering opportunities to review patient education materials, and improving care planning and shared decision making, as well as enhancing the overall patient centeredness of care.

Looking more broadly at our findings, it appears that changing an organization's culture may be key to improving acceptance of an inpatient portal. A recent systematic review by Dendere and colleagues to identify factors and best practices for successful inpatient portal implementation stated that organizational factors, including organizational culture, are the most critical for determining the successful acceptance and nature of portal implementation. ${ }^{31}$ Similarly, several researchers have highlighted the important role of culture in their assessment of inpatient portal implementation. $^{32-34}$ The themes we identified on the changing perspectives of care team members suggests that our AMC was experiencing a cultural transformation in "how things are perceived and done, ${ }^{35}$ where the introduction of the inpatient portal precipitated fundamental shifts in how care team members thought about and used a new technological application as part of the care process.

Other observations of portal implementations have also shown that the use of similar strategies to the ones deployed at an AMC (e.g., a continuous quality improvement process, clear communications, and use of specialist staff) in some combination contributes to successful change processes. ${ }^{32,36}$ McAlearney and colleagues noted in their study of healthcare organizational change that when deployed by an organization, these types of strategies should be coherent with the idiosyncrasies of that setting so that they can synergistically influence its people, processes, and perspectives. ${ }^{37} \mathrm{By}$ focusing on the patient centeredness of the inpatient portal, using a stakeholder group to steer change strategically and in a unified manner across the AMC, and through activities such as promoting shared responsibility, offering training, and providing communication guidelines, our AMC engaged deliberately in this change process. This focus should be considered in future implementation efforts.

For hospital operational teams, our results highlight explicit steps that can be taken to improve implementation of an inpatient portal. For instance, providing units with their provisioning rates had an important impact on the care team's acceptance of the new technology. This feedback of data encouraged them to make workflow changes, learn about the new technology, and ultimately helped support buy-in. Providing continual training for care team members had a similar effect, and helped them understand the utility of the technology for patients. These strategies, in addition to identifying champions, are critical to facilitate organizational change.

\section{Limitations}

Our study findings should be interpreted in light of several limitations. First, our study was limited to a single AMC, and, as a result, the findings may not be generalizable to other healthcare systems. The lack of generalizability, however, is weighed against our high internal validity: our study design, including sampling care team members across 53 units within the six hospitals that comprise the AMC across four unique interview time points, provides an in-depth examination of the organizational change experienced at the AMC. Nonetheless, we acknowledge that our recruitment approach was inclusive such that interviewees may have participated in multiple phases of interviews. Also, interviewees may have felt pressured to report that implementation progress had been positive. As a result, our assessment of implementation success may be favorably biased. Similar to the concerns about generalizability, our study examined a single inpatient portal application, MyChart Bedside. The interface of MyChart Bedside is unique, but many of its general functions and features are likely shared by other patient portals designed for the inpatient setting. As a result, our findings regarding organizational change related to the implementation of the new technology are likely applicable to hospitals implementing other inpatient portal applications.

In addition, as the focus of the present study was limited to our analysis of care team members' perspectives, we were unable to also consider the perspectives of patients about the inpatient portal. While we recognize that care team acceptance does not necessarily translate to patient uptake of the technology, our consideration of this issue in the context of 
organizational change supported our focused analysis. At the same time, given the breadth of this topic, we have conducted other analyses solely focused on patients' perspectives, ${ }^{15,16}$ and have noted the importance of developing implementation strategies that accommodate the varied needs of a diverse patient population. ${ }^{38-40}$ Finally, our study was not designed to assess causality between the three areas of organizational change and the six emergent strategies. These strategies emerged from our analysis as contributing to implementation success; yet, their development and operationalization was nonsystematic, and does not allow for testing the causal relationships. Nonetheless, given the depth and breadth of our study, we are confident that these strategies can help organizations succeed in the implementation of inpatient portals.

\section{Conclusion}

In our study of care team members' perceptions about the implementation of an inpatient portal, we found changes in attitudes about the new technology, in workflow, and in buyin of the portal itself as the organization made strategic efforts to accommodate this change. It is important for organizations to consider these strategies that can help improve acceptance of the new technology as they plan for the implementation of an inpatient portal.

\section{Clinical Relevance Statement}

Inpatient portal applications are becoming more widely utilized in hospital inpatient settings and are transforming the way patients are engaged in their healthcare. Implementation of an inpatient portal requires realignment of goals, changes in individuals, and processes that exist within a complex healthcare setting such as a hospital. We identified three major themes related to organizational changes in response to the implementation of an inpatient portal: (1) challenges with new technology, (2) impact of the portal on workflow, and (3) buy-in. Six strategies were identified as important for implementation success: (1) convene a stakeholder group, (2) offer continual portal training, (3) encourage shared responsibility, (4) identify champions, (5) provide provisioning feedback, and (6) support patient use.

\section{Multiple Choice Questions}

1. The primary aim of the stakeholder group at our AMC was to:

a. Enhance physicians' use of inpatient portals.

b. Address grievances from patients about inpatient portals.

c. Increase inpatient portal use throughout the AMC.

d. Design operational plans related to inpatient portal implementation across the institution.

Correct Answer: The correct answer is option c. In response to the challenges identified during the early post-implementation interviews, our AMC leadership established a stakeholder group 6 months after the implementation had begun. This team consisted of representatives from hospital leadership (e.g., executive director), nurse managers, faculty physicians, patient experience and education leadership, information technology representatives, and members of the research team. The aim of this stakeholder group was to increase inpatient portal use throughout the AMC. The stakeholder group met monthly to set goals and establish priorities around inpatient portal use, discuss tablet provisioning processes and rates of activation, and examine use of the available device functions. Additionally, the team receives, analyzes, and adjudicates new or modified requests for additional features or new functionality.

2. In addition to challenges with integrating the inpatient portal into workflow and issues related to inpatient portal buy-in, another critical barrier to inpatient portal acceptance during the early post-implementation phase was:
a. Difficulty with the new technology.
b. Collecting adequate data to evaluate its impact.
c. Sharing findings rapidly across providers.
d. Obtaining adequate funds to purchase more tablets.

Correct Answer: The correct answer is option a. During the early period following inpatient portal implementation, comments from care team members suggested they were concerned about their lack of familiarity with the new technology. This concern created anxiety and frustration as one nurse explained, "Honestly we rush through it, because it's a pain. You know? And, I wish there were someone that had time to spend with them, to show them." Similarly, another care team member noted, "It's just like when you have a busy assignment, that's the lowest priority thing that you're thinking about is like getting someone a tablet." Concerns about the new technology, however, were considerably less evident in the late post-implementation interviews. Care team members appeared more accepting of the new technology during these later interviews, with several noting there had been a positive impact of the portal implementation on the perspectives of both care team members and patients.

Protection of Human and Anmial Subject

Conduct of this research was reviewed and approved by The Ohio State University Institutional Review Board.

\section{Funding}

This work was supported by the Agency for Healthcare Research and Quality (AHRQ) grants R01HS024091, R21HS024767, and P30HS024379. While this research was funded by AHRQ, the study sponsor had no involvement in the collection, analysis, or interpretation of data; in the writing of this manuscript; or in the decision to submit the manuscript for publication. 
Conflict of Interest

None declared.

\section{Acknowledgments}

The authors wish to thank Dr. Timothy Huerta, Dr. Cynthia Sieck, Dr. Jennifer Hefner, Lindsey Sova, Jaclyn Volney, Shonda Vink, Dr. Sarah MacEwan, Danijela Cvijetinovic, Toby Weinert, Allison Silverman, Ayanna Scott, and Karen Alexander, all affiliated with the authors' organization at the time of this study, for their assistance with this project. They are also extremely grateful to the care team members who participated in this study.

\section{References}

1 Tai-Seale M, Downing NL, Jones VG, et al. Technology-enabled consumer engagement: promising practices at four health care delivery organizations. Health Aff(Millwood) 2019;38(03):383-390

2 Ghafur S, Schneider EC. Engaging patients using digital technology - learning from other industries. NEJM Catalyst 2019. Available at: https://catalyst.nejm.org/patients-digital-consumer-focusedindustries. Accessed October 7, 2019

3 Ahern DK, Woods SS, Lightowler MC, Finley SW, Houston TK. Promise of and potential for patient-facing technologies to enable meaningful use. Am J Prev Med 2011;40(05, Suppl 2):S162-S172

4 Hefner JL, Sieck CJ, McAlearney AS. Training to optimize collaborative use of an inpatient portal. Appl Clin Inform 2018;9(03): 558-564

5 Kelly MM, Hoonakker PLT, Coller RJ. Inpatients sign on: an opportunity to engage hospitalized patients and caregivers using inpatient portals. Med Care 2019;57(02):98-100

6 Huerta T, Fareed N, Hefner JL, et al. Patient engagement as measured by inpatient portal use: methodology for log file analysis. J Med Internet Res 2019;21(03):e10957

7 Masterson Creber RM, Grossman LV, Ryan B, et al. Engaging hospitalized patients with personalized health information: a randomized trial of an inpatient portal. J Am Med Inform Assoc 2019;26(02):115-123

8 Fareed N, Walker D, Sieck CJ, et al. Inpatient portal clusters: identifying user groups based on portal features. J Am Med Inform Assoc 2019;26(01):28-36

9 Sieck CJ, Walker DM, Hefner JL, Volney J, Huerta TR, McAlearney AS. Understanding secure messaging in the inpatient environment: a new avenue for communication and patient engagement. Appl Clin Inform 2018;9(04):860-868

10 Kelly MM, Hoonakker PL, Dean SM. Using an inpatient portal to engage families in pediatric hospital care. J Am Med Inform Assoc 2017;24(01):153-161

11 Walker DM, Menser T, Yen PY, McAlearney AS. Optimizing the user experience: identifying opportunities to improve use of an inpatient portal. Appl Clin Inform 2018;9(01):105-113

12 Yen PY, Walker DM, Smith JMG, Zhou MP, Menser TL, McAlearney AS. Usability evaluation of a commercial inpatient portal. Int J Med Inform 2018;110:10-18

13 Haun JN, Lind JD, Shimada SL, et al. Evaluating user experiences of the secure messaging tool on the Veterans Affairs' patient portal system. J Med Internet Res 2014;16(03):e75

14 Ali SB, Romero J, Morrison K, Hafeez B, Ancker JS. Focus section health IT usability: applying a task-technology fit model to adapt an electronic patient portal for patient work. Appl Clin Inform 2018;9(01):174-184

15 McAlearney AS, Fareed N, Gaughan A, MacEwan SR, Volney J, Sieck CJ. Empowering patients during hospitalization: perspectives on inpatient portal use. Appl Clin Inform 2019;10(01):103-112
16 McAlearney AS, Sieck CJ, Gaughan A, Fareed N, Volney J, Huerta TR. Patients' perceptions of portal use across care settings: qualitative study. J Med Internet Res 2019;21(06):e13126

17 Woollen J, Prey J, Wilcox L, et al. Patient experiences using an inpatient personal health record. Appl Clin Inform 2016;7(02): 446-460

18 Wieland D, Gibeau A, Dewey C, Roshto M, Frankel H. Patient portal readiness among postpartum patients in a safety net setting. Appl Clin Inform 2017;8(03):698-709

19 McAlearney AS, Gaughan A, MacEwan SR, Fareed N, Huerta TR. Improving acceptance of inpatient portals: patients' and care team members' perspectives. Telemed J E Health 2019. Doi: 10.1089/tmj.2019.0026

20 Hoonakker PLT, Rankin RJ, Passini JC, et al. Nurses' expectations of an inpatient portal for hospitalized patients and caregivers. Appl Clin Inform 2019;10(04):625-633

21 Hefner JL, Sieck CJ, Walker DM, Huerta TR, McAlearney AS. System-wide inpatient portal implementation: survey of health care team perceptions. JMIR Med Inform 2017;5(03):e31

22 Kelly MM, Dean SM, Carayon P, Wetterneck TB, Hoonakker PL. Healthcare team perceptions of a portal for parents of hospitalized children before and after implementation. Appl Clin Inform 2017;8(01):265-278

23 Collins S, Dykes P, Bates DW, et al. An informatics research agenda to support patient and family empowerment and engagement in care and recovery during and after hospitalization. J Am Med Inform Assoc 2018;25(02):206-209

24 Walker DM, Hefner JL, Sieck CJ, Huerta TR, McAlearney AS. Framework for evaluating and implementing inpatient portals: a multi-stakeholder perspective. J Med Syst 2018;42(09):158

25 Collins SA, Rozenblum R, Leung WY, et al. Acute care patient portals: a qualitative study of stakeholder perspectives on current practices. J Am Med Inform Assoc 2017;24(e1):e9-e17

26 McAlearney AS, Hefner JL, Sieck CJ, Huerta TR. The journey through grief: insights from a qualitative study of electronic health record implementation. Health Serv Res 2015;50(02): 462-488

27 Miles MB, Huberman AM. Qualitative Data Analysis: an Expanded Sourcebook. Thousand Oaks, CA: Sage Publications; 1994

28 Crabtree BF, Miller WL. Using codes and code manuals: a template organizing style of interpretation. Doing Qualitative Research 1999;2:163-177

29 Glaser BG, Strauss AL. The Discovery of Grounded Theory: Strategies for Qualitative Research. Chicago, IL: Aldine Publishing Company; 1967

30 ATLAS.ti. Version 8.3.1. Berlin: Scientific Software Development $\mathrm{GmbH} ; 2013$

31 Dendere R, Slade C, Burton-Jones A, Sullivan C, Staib A, Janda M. Patient portals facilitating engagement with inpatient electronic medical records: a systematic review. J Med Internet Res 2019;21 (04):e12779

32 Baldwin JL, Singh H, Sittig DF, Giardina TD. Patient portals and health apps: pitfalls, promises, and what one might learn from the other. Healthc (Amst) 2017;5(03):81-85

33 Shah SD, Liebovitz D. It takes two to tango: engaging patients and providers with portals. PM R 2017;9(5S):S85-S97

34 Morrow D, Hasegawa-Johnson M, Huang T, et al. A multidisciplinary approach to designing and evaluating electronic medical record portal messages that support patient self-care. J Biomed Inform 2017;69:63-74

35 Schein EH. Organizational Culture. Vol 45. American Psychological Association; 1990

36 Otte-Trojel T, Rundall TG, de Bont A, van de Klundert J, Reed ME. The organizational dynamics enabling patient portal impacts upon organizational performance and patient health: a qualitative study of Kaiser Permanente. BMC Health Serv Res 2015; $15: 559$ 
908 Facilitating Change to Accommodate a Portal Walker et al.

37 McAlearney AS, Terris D, Hardacre J, et al. Organizational coherence in health care organizations: conceptual guidance to facilitate quality improvement and organizational change. Qual Manag Health Care 2013;22(02):86-99

38 Grossman LV, Masterson Creber RM, Ancker JS, et al. Technology access, technical assistance, and disparities in inpatient portal use. Appl Clin Inform 2019;10(01):40-50
39 Walker DM, Hefner JL, Fareed N, Huerta TR, McAlearney AS. Exploring the digital divide: age and race disparities in use of an inpatient portal. Telemed J E Health 2019. Doi: 10.1089/tmj.2019.0065

40 Stein JN, Klein JW, Payne TH, et al. Communicating with vulnerable patient populations: a randomized intervention to teach inpatients to use the electronic patient portal. Appl Clin Inform 2018;9(04):875-883 